\title{
Optimization Dispatching of Express Logistics in E-commerce Environment
}

\author{
Songjie Gong, Suli Ye \\ Zhejiang Business Technology Institute, Ningbo, 315012, China \\ email:songjie_gong@163.com
}

Keywords: E-commerce environment, optimization, dispatching, express logistics.

\begin{abstract}
At present, the contradiction between the surging e-commerce demand in Zhejiang Province and the inadequate express logistics service capability, express delay and poor service quality has become increasingly prominent. There is a significant difference between express logistics and traditional logistics under e-commerce environment. Based on the practice of e-commerce, this project synthetically explores the delivery strategy and route optimization method of express delivery under dynamic network structure by using multi-disciplinary cross-method, and puts forward the emergency dispatching strategy and route optimization method of express logistics in response to various uncertain events. A fast collaborative optimization mechanism for express logistics is developed considering the requirements of highly coordinated and cohesive system. In order to preliminarily establish and improve the theory and technology system of express logistics management suitable for the background, reduce the overall operating cost of express logistics, enhance the core competitiveness of related enterprises, and promote the further development of express logistics industry.
\end{abstract}

\section{Introduction}

With the rapid development of e-commerce market, consumer demand for express logistics is increasing rapidly. State-owned enterprises, international logistics enterprises and private express logistics enterprises have formed a tripartite situation. Especially after the "Postal Law" established the legal status of private express delivery, the express logistics industry has developed rapidly. Among the top 10 private express delivery companies in China, Zhejiang businessmen occupied 7 seats. For example, private express delivery, known as "four links and one reach", came from Zhejiang.

The so-called express logistics, is a new type of modern logistics service model, is to provide the community with a rapid integration of service activities for the general term. Compared with traditional logistics, express logistics has its particularity. First, express logistics presents a complex dynamic network structure. Express logistics customers are large in scale and small in batches, so that a large number of goods and consumers are distributed in different geographical locations, the production of these customers has a great randomness, each time the customers will be different, their location and distribution requirements are not consistent. Second, uncertainty events occur frequently. Courier logistics is also often faced with various emergencies, natural disasters, climate and environmental factors. In addition, the sudden growth of sales promotion and seasonal demand will also test the express logistics. Third, the problem of system collaboration and convergence is outstanding. Express logistics provides door-to-door service for customers through the integration of ordering, transportation, and warehousing and distribution links. Close cooperation among all links is the fundamental guarantee to improve the efficiency of express delivery. Fourth, high timeliness requirements and speed is the soul of express logistics. Express service has rigid time constraints. The whole process time limit standard of the same express product is unified in the whole network of the enterprise.

The particularity of express logistics in E-commerce environment, such as network structure, uncertain events, system coordination and convergence, and timeliness, poses great challenges to the 
dispatch and coordination optimization of express logistics. Compared with the ease and convenience of e-commerce online shopping experience and the explosion of online transactions, the online physical express logistics capacity is inadequate, serious delays, delivery accuracy is poor, which has become a bottleneck of online shopping by consumers. According to the statistics of the State Post Office, 58.6\% of consumers' complaints about express business are about express mail. Delays and absolute numbers are increasing at a rate of $30 \%$. The inadequate service capacity and the extrusion delay of express logistics have resulted in bad consumer experience, inefficient e-commerce and limited e-commerce transactions. It has become an important issue in the public basic service system which affects economic development and people's livelihood.

\section{Project background}

Although the logistics scheduling optimization has achieved fruitful results, the E-commerce environment of express logistics has put forward new challenges to the existing logistics scheduling research. Firstly, the number of customers involved in express logistics service scheduling is much larger than the traditional scheduling problem, which makes it more difficult to solve the NP-hard scheduling problem; secondly, the location of customers and the customer's demand for service time are often random in express logistics; thirdly, many external events. The occurrence of items, such as promotions or seasonal fluctuations in demand, rain and snow weather delays on flights and so on, directly test the express logistics, need to respond quickly to it. Therefore, how to design a simple and effective dispatching optimization strategy according to the above characteristics of modern express logistics, so that express logistics can make rapid response to customers in the shortest time and achieve economic feasibility, is a problem worthy of study.

The particularity of express logistics in E-commerce environment, such as network structure, uncertain events, system coordination and convergence, and timeliness, poses great challenges to the dispatch and coordination optimization of express logistics. Compared with the ease and convenience of e-commerce online shopping experience and the explosion of online transactions, the online physical express logistics capacity is insufficient, serious delays, delivery accuracy is poor, which has become a bottleneck of online shopping by consumers. The inadequate service capacity and the extrusion delay of express logistics have resulted in bad consumer experience, inefficient e-commerce and limited e-commerce transactions. It has become an important issue in the public basic service system which affects economic development and people's livelihood.

The particularity of express logistics in e-commerce environment makes the previous research results of traditional logistics scheduling and collaborative optimization lose the premise foundation. At present, the academic circles lack a clear and complete system analysis framework and method for the new type of express logistics scheduling and collaborative optimization. Generally speaking, the express logistics industry has some shortcomings, such as high comprehensive cost, low service quality and weak technical means, which are extremely inadaptable to the economic and social demand for express logistics, but also seriously restrict the development of express logistics industry. With the rapid development of e-commerce as the background, this project studies the dispatching and collaborative optimization in the field of express logistics management to enhance the core competitiveness of related enterprises and promote the development of express logistics industry.

\section{Delivery strategy and route optimization of express logistics under dynamic network}

Drawing lessons from vendor managed inventory, logistics centralized distribution center operation mode and cyclic pick-up mode, we focus on whether express logistics providers can provide a delivery service managed by express logistics service providers, and whether they can find an effective real-time pick-up strategy to implement the service under the dynamic network structure to make it faster. Delivery logistics providers can greatly reduce the logistics costs required for picking up goods without reducing or even improving their service quality to the merchants. In addition, corresponding to the corresponding real-time pickup strategy, the corresponding real-time 
route optimization is needed to reduce the pickup cost.

\section{Research on emergency logistics dispatching strategy based on risk analysis}

For express logistics services, all kinds of uncertainty events occur frequently. For example, weather causes related flights to be delayed or even grounded, commercial promotions and holiday factors make customer demand multiplied or even multiplied. Aiming at the special environment of express logistics under E-commerce environment, this paper analyzes and identifies various internal and external factors that affect the efficiency and capacity of express logistics, and analyzes the extent of the impact of various possible events on express logistics. Especially, this paper analyzes the changes of express logistics information caused by uncertain events, such as delivery time, delivery cost, and customer demand and so on, and calculates the interval values of these uncertainties. On this basis, using the uncertain interval number optimization theory, an emergency dispatching strategy with uncertain interval number is proposed. Considering the speediness of express logistics distribution, the quality of express service is not reduced as far as possible, and the logistics cost of emergency dispatching can be minimized. This is very important for express logistics service.

\section{Fast collaborative optimization of express logistics based on time and cost}

Many logistics links have formed different subsystems. The subsystems have multi-level structure. The subsystems at the bottom can be divided into several activity sequences, and these subsystems often belong to the same express logistics enterprise. The high degree of coordination and cohesion of all links in the whole system is the fundamental guarantee for improving the efficiency of express logistics. Based on the resource-constrained project scheduling theory, this paper studies the system decomposition and partitioning methods of express logistics. On the one hand, the activities of express logistics are systematically sorted and classified by decomposition and partitioning, which provides the basis for future research. On the other hand, the collaborative optimization based on the system decomposition helps to reduce the complexity of the problem. On this basis, considering the high urgency of express logistics on the time requirement, it is our concern to explore the coordination and optimization mechanism to achieve rapid coordination and convergence of various subsystems, and to improve the system service level and reduce the cost of service.

\section{Specific technical line and steps}

(1) First step: practice research and literature collection.

This paper investigates and analyzes the practices of enterprises, focusing on the problems and solutions of operation scheduling and collaborative optimization encountered by related express logistics enterprises in providing express logistics services; combs, digests and absorbs relevant research achievements in modern logistics management, e-commerce, emergency management and other fields to lay a solid foundation for the smooth development of the project.

(2) Second step: Express Logistics picking strategy and route optimization under dynamic network.

To solve this problem, the project solution is to present a divide-and-conquer regionalized integration scheme, as shown in Figure 2. The basic idea of this scheme is to first use data mining, combined with geographic information system, to decompose the customer into several regions at a certain granularity. On this basis, considering that the service quality of express delivery company is related to the time window required by customers, the real-time route optimization based on time window is studied by using dynamic programming and intelligent optimization technology. Through the above method, the number of nodes can be greatly reduced, and the optimization scheme to meet the application requirements is given.

(3) Third step: Emergency Logistics Emergency Scheduling Strategy Based on risk analysis 
Traditional uncertain optimization methods are mainly stochastic programming and fuzzy programming, which need a lot of uncertain information to construct accurate probability distribution or fuzzy membership function of variables. However, for some uncertain events of express logistics, it is very difficult or costly to obtain sufficient uncertain information, which makes the applicability of the first two methods have certain limitations. In contrast, interval number optimization is a new kind of uncertain optimization method. It uses interval to describe the uncertainties of variables. It only needs less information to obtain the upper and lower bounds of variables. It embodies good simplicity and economy in modeling.

\section{Summary}

The real-time pick-up strategy and route optimization model based on dynamic network and time window proposed in this project can describe the dynamic pick-up service process of express logistics more truly than the traditional logistics scheduling model with a few nodes and static network. In addition, a new customer regionalization integration plan is expected to improve and perfect the line optimization algorithm.

Compared with the traditional stochastic programming and fuzzy programming methods, the uncertain optimization method based on interval number is helpful to improve the simplicity and economy of the modeling of Express Logistics Emergency dispatching, and is more suitable for the rapid emergency dispatching decision-making requirements under the uncertain environment of express logistics.

\section{Acknowledgement}

Supported by University Students' Innovative Undertaking Project of Zhejiang Business Technology Institute

Programs Supported by Ningbo Soft Science Research Program(Grant No. 2015A10025).

\section{References}

[1] Tseng Y, Yue W L, Taylor M A P. The role of transportation in logistics chain[C]. Eastern Asia Society for Transportation Studies, 2005.

[2] Jiang Z, Wang D. Model and algorithm for logistics distribution routing of B2C e-commerce [J]. INFORMATION AND CONTROL-SHENYANG-, 2005, 34(4): 481.

[3] Lau H C W, Jiang Z Z, Ip W H, et al. A credibility-based fuzzy location model with Hurwicz criteria for the design of distribution systems in B2C e-commerce [J]. Computers \& Industrial Engineering, 2010, 59(4): 873-886.

[4] Bask A, Lipponen M, Tinnilä M. E-commerce logistics: a literature research review and topics for future research [J]. International Journal of E-Services and Mobile Applications (IJESMA), 2012, 4(3): 1-22.

[5] Sitek P, Wikarek J. A hybrid approach to the optimization of multiechelon systems [J]. Mathematical Problems in Engineering, 2015, 2015.

[6] Kohn C, Brodin M H. Centralised distribution systems and the environment: how increased transport work can decrease the environmental impact of logistics [J]. International Journal of Logistics: Research and Applications, 2008, 11(3): 229-245.

[7] Wang Y, Ma X, Lao Y, et al. A fuzzy-based customer clustering approach with hierarchical structure for logistics network optimization [J]. Expert Systems with Applications, 2014, 41(2): 521-534. 